\title{
Evaluation of the Structural Changes of Extremely Low Frequency Electromagnetic Fields on Brain and Testes of Adult Male Mice
}

\author{
Aisha A. Saad El-Din*, Nabila A. Abd El-Motaal* \\ Haidy F. Abd El Hamid** Yasser F. El-Akid*** \\ *National Centre of Radiation Research and Technology, Egypt, **Department of \\ Anatomy, ***Department of Forensic Medicine and Clinical Toxicology, Faculty of \\ Medicine, Ain Shams University.
}

\begin{abstract}
The increasing number of devices emitting magnetic fields raised valid questions concerning their safety and potential risk for human exposure and its limits. For this purpose fifteen adult mice were exposed to extremely low frequency electromagnetic field (ELMF) at a frequency of $60 \mathrm{Hertz}(\mathrm{Hz})$ and intensity of 20 millitesla $(\mathrm{mT})$ for 2 hours for 2 consecutive days. Other 10 animals served as a control.

After their sacrifice, serum testosterone was determined. In addition, electron microscopic study of mice brains and testes was done.

The present study revealed that exposure to EMF caused significant increase in serum testosterone.

Electron microscopic examination of brain cells showed marked demyelination of nerve fibres with degeneration of nerve cells. There was also degeneration of some spermatogenic cells with abnormal sperm morphology.

In conclusion, the present study showed evident biochemical and histopathological changes of ELMF on the brain and testis. Further studies would be useful to assess the effect of other doses of exposure and to follow the degree of reversibility of these changes. Other investigations are also advisable to minimize the above biological effects and protect against ELMF.
\end{abstract}

\section{Introduction}

The term electromagnetic field is applied to a type of energy that is beamed through the air, having two components, an electric field and another magnetic one. The electric component influences primarily particles of the surface of nearby object, while the magnetic field penetrates to the interior (Santini et al. 2005). High magnetic field strengths may be encountered near switching stations, research facilities and video display terminals (David et al., 2002).Moreover, application of magnetic field devices in medicine as a diagnostic tool (magnetic resonance imaging or magnetic resonance spectroscopy used to study tissue metabolism) or as therapeutic techniques (to enhance bone fracture healing and tissue regeneration), increased the chance of exposure to magnetic fields (Otter et al., 1998).On a daily basis, exposure to extremely low frequency electromagnetic field (ELMF) produced by household wiring and fluorescent lighting is common. Other sources are any appliances that are plugged into the wall or battery operated. In addition, electric clocks and clock radio have been mentioned as major sources of night time exposure of children (Preece, 1997).

The increasing numbers of devices emitting magnetic fields raised a valid question concerning their safety and the potential risk of human exposure and its limits (Valberg, 1996). During the past 20years a number of studies have suggested an increased risk of cancer induced by electromagnetic fields (Yasui, 1997 and Simko, 2004). The National Institute of Environmental Health Science (NIEHS) declared that ElMF should be regarded as a 
potential carcinogen. The existing evidences require more research efforts on the possible health impact of ElMF regarding adequate exposure and dose assessment (Boorman et al., 2002).

Reviewing the literature, it was found that tissues with higher hydration as brain and testis were more sensitive to magnetic field (Arutiunian et al., 1998), yet many controversies regarding the biological effects on these organs were encountered. Schirimacher et al. (2000) reported increased permeability of blood brain barrier (BBB) on exposure to magnetic field. On the contrary, Kuribayashi et al.(2005) declared that neither BBB related gene or vascular permeability were affected by exposure. Some investigators reported affection of testicular germ cell (Lee et al., 2004), while others denied any magnetic field exposure related histopathological alteration in testicles of mice (Forgacs et al., 2004).

So, the aim of this study is to demonstrate the biological effects of extremely low frequency ElMF on the brains and testes of mice to emphasize its potential risk and throw more light on such controversies.

\section{Materials And Methods}

\section{Experimental animals and method of exposure}

Twenty-five adult male mice weighing between 20-30 grams were employed. They were obtained from the animal house of National Centre for Radiation Research and Technology, Cairo (NCRRT). The animals were divided into two groups. The first group served as a healthy control group and consisted of 10 animals. The second group included 15 animals exposed to ELMF at frequency of $60 \mathrm{Hertz}(\mathrm{Hz})$ and intensity of 20 millitesla (mT) for 2 hours and for two consecutive days using a modified exposure system which was designed and constructed locally in NCRRT (Saad El- Din et al., 2000).The system included a water-cooled wooden cage surrounded with an electromagnet that consisted of three parallel closely connected rectangular coils. A computer program was designed to calculate the field strength in the cage. This allowed regular and equal exposure of large number of animals. Food and water were kept in special open containers fixed in the cages. Cleaning and changing water and food were done for all animals twice daily. Animals of the control group were housed in a similar cage, kept during the run of the experiment in a typical chamber having the same dimensions of the exposure facility.

\section{Experimental biochemical parameters Serum testosterone}

On the third day, the animals were anesthetized by ether and blood was obtained from the heart directly by needle aspiration. The blood samples were centrifuged and serum was separated for the radioimmunoassay of testosterone (Mc Carm et al., 1985)..

\section{Histopathological examination}

\section{A. Extraction of the brain}

After obtaining the blood samples, intracardiac perfusion of 0.5 c.c. of the fixative(buffered glutaraldhyde $2.5 \%$ ) was done followed immediately by decapitation. The soft tissue of the scalp was removed, followed by removal of the skull cap by a midline incision extending from the foramen magnum to the nose along the sagittal suture then careful removal of the bone around. Some of the fixative used was added during the dissection to avoid rapid autolysis. The brains were extracted. Small cubes of $1 \mathrm{~mm}$ in dimension were cut using a sharp razor from the cortex of cerebral hemispheres at an area near the middle line and that corresponds to the coronal suture, with careful manipulation to avoid disturbance in the tissue structure.

\section{B. Extraction of the testes}

As regards the testes, immediately after sacrifice, they were dissected out and decapsulated, put in a fixative (buffered glutaraldehyde $2.5 \%$ ) for one hour and then cubes of $1 \mathrm{~mm}$ in dimension were cut by a sharp razor from the outer layer of the testes with careful manipulation, too. 


\section{Processing for transmission electron microscopy}

The small cubes of both the brain and testis were then fixed in $2.5 \%$ glutaraldehyde for 24hours then washed by phosphate buffer ( $\mathrm{pH}$ 7.4) three times, 10 minutes for each. The slices were then fixed in $1 \%$ osmium tetroxide for one hour then rewashed in phosphate buffer in the same sequence. The samples were then dehydrated by gradually increasing concentrations of ethyl alcohol for $1 / 2$ hour each time and then kept in absolute alcohol for one hour. The samples were then treated with propylene oxide and then embedded in spurr resin to form gelatin blocks. Blocks obtained were trimmed under binocular microscope and semithin sections were cut using LKB microtome. The semithin sections $(1 \mu \mathrm{m}$ thick) were stained by $1 \%$ toluidine blue stain and examined under light microscope for general orientation before ultrathin sectioning. Then, ultra thin sections $\left(300 \mathrm{~A}^{\circ}\right)$ were cut and picked up on copper grids.They were double stained by uranyl acetate and lead citrate (Hayat, 1989).The stained sections were examined and photographed by transmission electron microscope (Philips-CM 100) at the Electron Microscope Unit, Anatomy Department, Faculty of Medicine, Ain Shams University.

\section{Statistical analysis:}

The obtained biochemical results were statistically analyzed using Student "t" test, where P-value $<0.05$ was considered significant (Altman, 1994).

\section{Results}

\section{Biochemical Results:}

The present work revealed significant increase in serum testosterone in the exposed group (group II) when compared with the control group (group I) (table 1).

\section{Histopathological Results:}

\section{A. Brain}

The cerebral hemispheres of the control adult mice consisted of a cortex of grey matter overlying a central mass of white matter. Histologically, they were composed of neurones, supporting cells of central nervous system (glial cells) and blood vessels. The grey matter contained most of the neurone cell bodies while the white matter contained the axons. The cell body of the neurone possessed a large rounded euchromatic nucleus with prominent nucleolus surrounded by cytoplasm containing various organelles as rough endoplasmic reticulum, numerous scattered mitochondria, lysosomes, free ribosomes, neurofilaments, microtubules and Golgi apparatus. The surrounding axons forming nerve fibres contained mitochondria, neurofilaments and microtubules (fig.1). Blood capillaries of the continuous type were also encountered. They were lined by endothelial cells that encircled the capillary lumen, their plasma membranes approximating one another very closely and were bound together by tight junctions. Small cytoplasmic flaps called marginal folds or filopodia extended across the intercellular junctions. The capillary endothelium was supported by thin basal lamina (fig.2). The axons were seen either myelinated or non- myelinated. The control myelin sheath was formed of regularly arranged concentric lamellae that acquired either oval or rounded contour in cross section .These lamellae showed dense regular period lines alternating with less dense intra-period lines (fig.3).

Effect of ELMF on the cerebral hemisphere was most evident on some nerve cells which showed signs of degeneration of cell organelles especially at the peri-nuclear region. Degenerating mitochondria showing disrupted cristae and vacuolation were encountered in the cytoplasm. Some of the surrounding unmyelinated axons appeared with pale cytoplasm and affected neurofilaments and microtubules. Others remained intact while few thinnly myelinated axons appeared affected (fig.4).As regards the blood capillaries, junctions between endothelial cells were noticed with filopodia seen across these intercellular junctions. Vacuolation was seen in the perivascular area (fig.5). The myelin sheath showed also evident degenerative changes in the form of 
disruption with no differentiation between period and intra-period lines. Multiple interrupting large vacuoles appeared within the sheath (fig.6).Other myelin sheathes showed separation of their lamellae which was either focal or diffuse throughout the whole cross sections (fig.7).

\section{B-Testis}

Electron microscopic examination of the testis of the control adult mice showed that the seminiferous tubules were lined with a complex stratified epithelium consisting of spermatogenic cells at different stages of differentiation together with supporting Sertoli cells. The seminiferous tubules were encircled by a thin basal lamina with a sheath of myoid cells outside this lamina. The Sertoli cells showed irregular nuclei with a notable deep infolding of the nuclear membrane, situated in close proximity to the basement membrane together with adjacent spermatogonia (fig.8). Primary spermatocytes were also seen as large rounded cells with rounded nuclei and copious cytoplasm containing different cell organelles. The mitochondria were seen with short ill defined cristae (fig.8, 9). The ultra structural feature of the mature sperm was also observed; the head, neck middle piece and tail. The head showed deeply condensed nucleus with acrosomal cap while the middle piece showed central microtubules, peripheral microtubules and outer dense fibres surrounded by mitochondrial sheath (fig.10 $\mathrm{a} \& \mathrm{~b})$. Interstitial cell of Leydig was encountered in the section with large eccentric nucleus, and microvilli protruding from the cell. The cytoplasm contained moderate amount of lipid droplets, numerous mitochondria and profuse smooth endoplasmic reticulum (fig.11).

The exposed testis to ELMF showed variable degenerative changes within the seminferous tubules. Some Sertoli cells showed pale nucleus, electron lucent areas and vacuolation within the cytoplasm. Multiple vacuolated degenerated mitochondria were encountered with the presence of lysosomes and multivesicular bodies (fig.12, 13).Dilated smooth endoplasmic reticulum and separation of some Sertoli cell from the basal lamina with disruption of collagen fibers were also seen (fig.12). Some primary spermatocytes showed irregular shrunken pyknotic nuclei, vacuolation in the cytoplasm, dilatation of endoplasmic reticulum and presence of lysosomes (fig.14). Sperm abnormalities were noticed in the form of abnormal heads (fig.15). The interstitial cell of Leydig of the exposed group showed dilated smooth endoplasmic reticulum and numerous lipid droplets in the cytoplasm. The mitochondria and the lysosomes were within normal (fig.16).

Table (1): Student " $t$ " test statistical analysis of serum testosterone of the control group (group I: consisted of 10 animals) and EMF exposed group (group II: consisted of 15 animals).

\begin{tabular}{||l|l|l|l|l||}
\hline & Control group (I) & Exposed group (II) & \multirow{2}{*}{ t } & \multirow{2}{*}{ p } \\
\cline { 2 - 4 } & Mean \pm SD & Mean \pm SD & \multirow{2}{*}{2.9} & $<0.05$ \\
\hline \multirow{2}{*}{ Testosterone mg/dl } & $0.46 \pm 0.13$ & $0.84 \pm 0.25$ & & \\
\hline
\end{tabular}

t: Comparison between exposed and control groups.

$\mathrm{p}<0.05$ significant difference. 

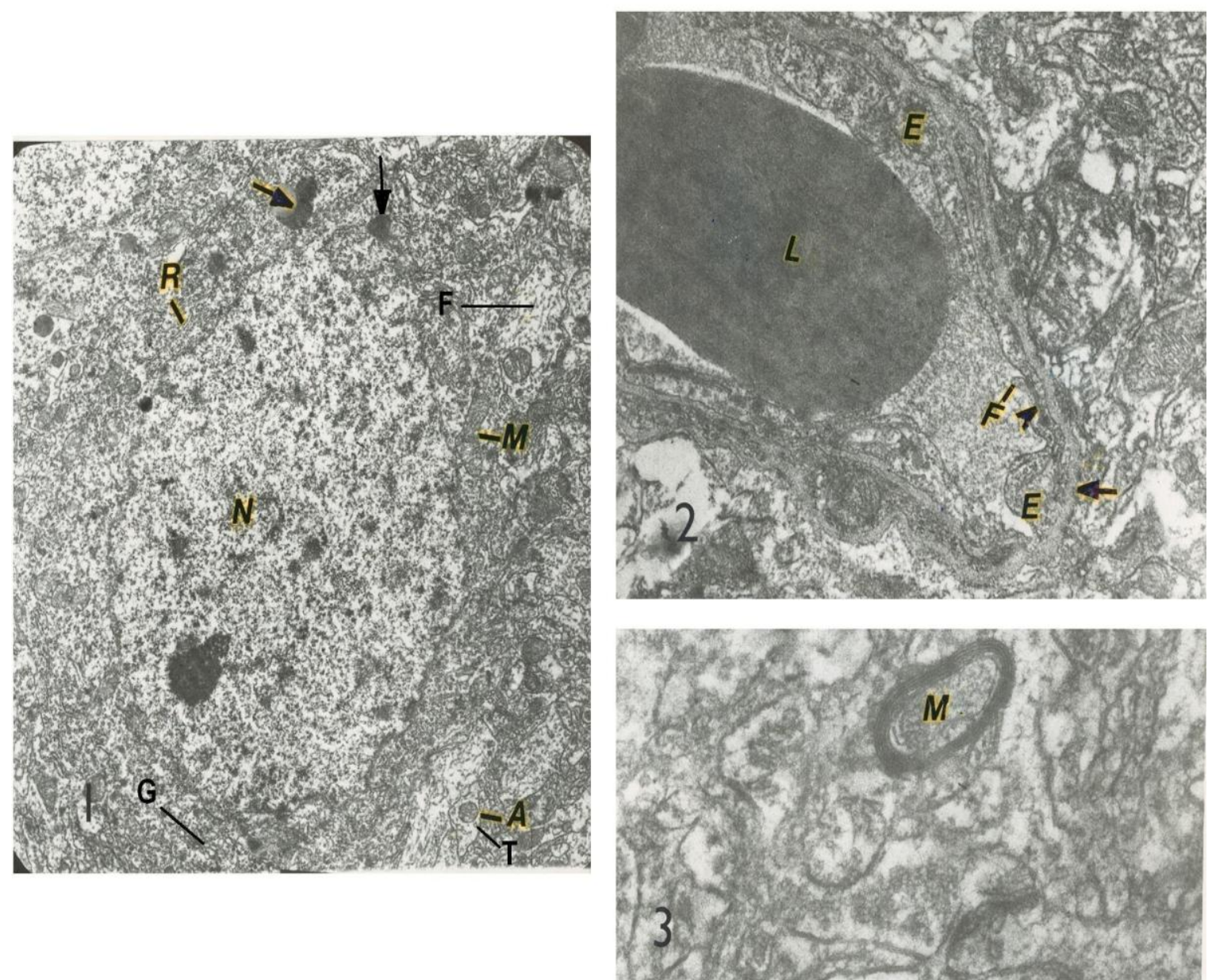

Plate I: Eelectron micrographs of sections of cerebral hemisphere of adult control mice showing:

Fig. [1]: Part of the cell body of a neuron with euchromatic large rounded nucleus $(\mathrm{N})$ and prominent nucleolus. Notice scattered mitochondria $(\mathrm{M})$, clusters of rough endoplasmic reticulum(R),Golgi apparatus (G) and lysosome $(\rightarrow)$ in the cytoplasm. Notice also surrounding axons (A) containing mitochondria, neurofilaments(F) and microtubules(T).

Fig. [2]: Continuous type of blood capillary. Notice two adjacent endothelial cells (E) bound together by tight junction $(>)$ with filopodia $(F)$ overhanging. The endothelium is surrounded by basal lamina $(\rightarrow)$ enclosing a lumen (L) containing a red blood cell.

Fig. [3]: Intact myelinated (m) nerve fibre. Note the concentric regularly arranged lamellae of the myelin sheath showing period and intra-period lines. 


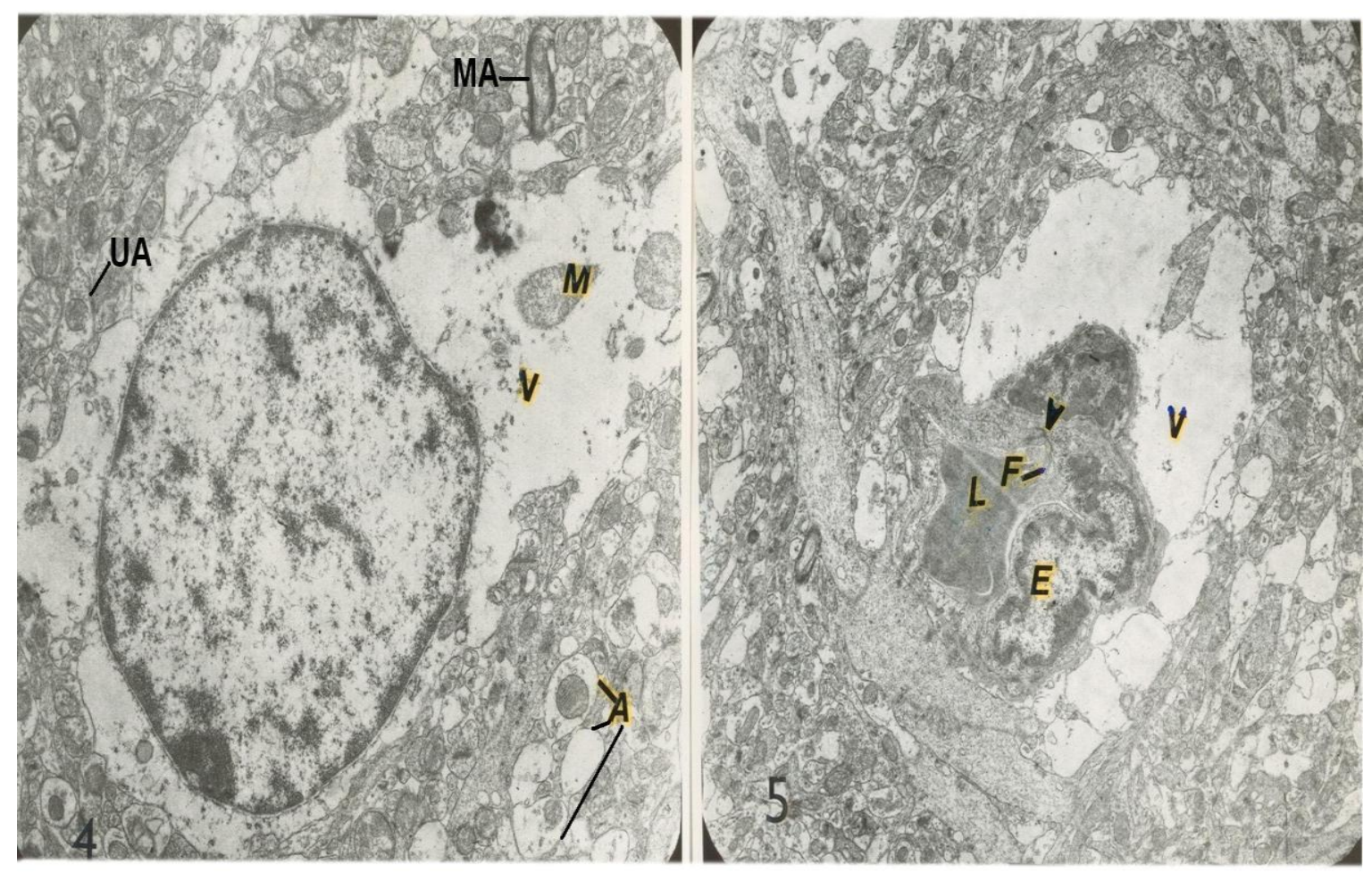

Plate II: Eelectron micrographs of sections of exposed cerebral hemisphere of adult mice showing:

Fig. [4]: Degenerating nerve cell with electron lucent areas (v) and degenerated cell organelles especially at the perinuclear region. Notice degenerating mitochondria $(\mathrm{M})$ with disrupted cristae and vacuolation. Notice also pale cytoplasm of surrounding unmyelinated axons (A) with affected neurofilaments and microtubules and the affected other thinnly myelinated axons(MA).Intact unmyelinated axons(UA)are also seen.

$$
\text { (x4000) }
$$

Fig. [5]: Continuous type of blood capillary lined with endothelial cell (E) surrounding lumen $(\mathrm{L})$ containing a red blood cell. Notice filopodia $(\mathrm{F})$ overhanging intact intercellular junction $(>)$. Vacuolation $(\mathrm{V})$ is seen in perivascular area. 

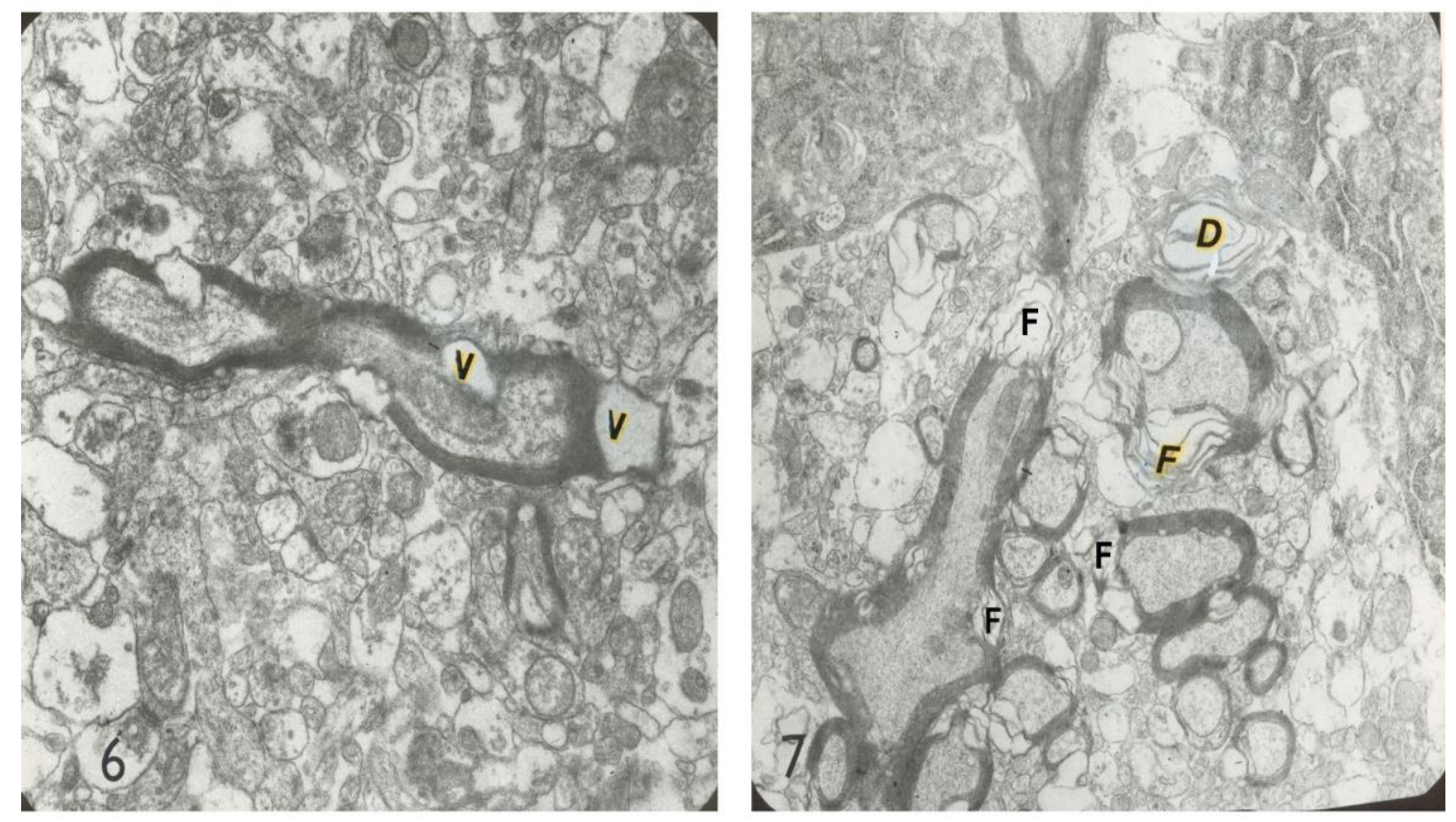

Plate III: Electron micrographs of sections of exposed cerebral hemisphere of adult mice showing degenerative signs of myelin sheath:

Fig. [6]: Notice the presence of interrupting vacuoles (v) within the sheath with loss of differentiation between period and intraperiod lines.

(x8000)

Fig .[7]: Notice the interrupted cross section of myelin sheath with focal (F) or diffuse (D) separation of lamellae.

(x4000) 

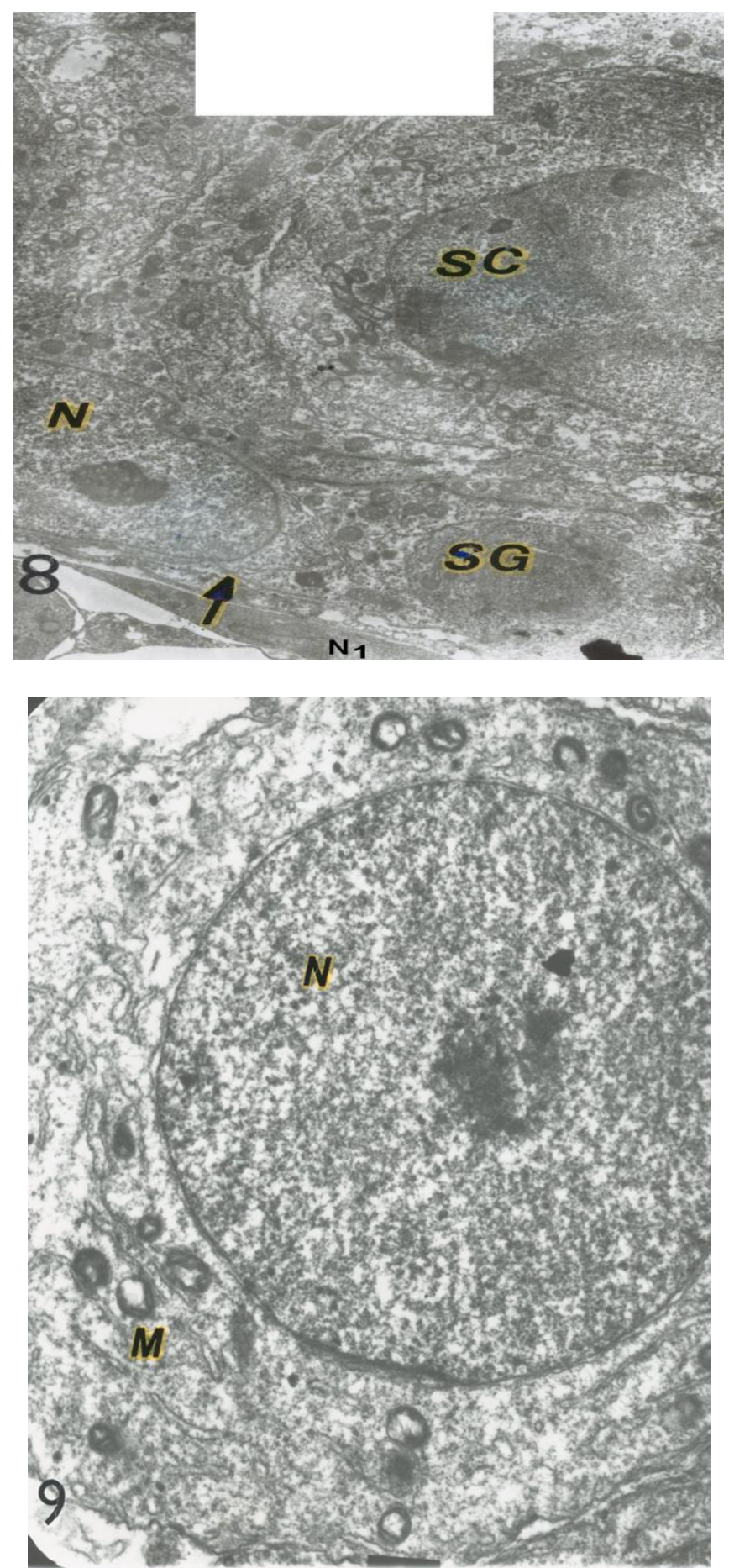

Plate IV: Electron micrographs of sections of testes of control adult mice showing:

Fig. [8]: Part of a seminiferous tubule. Notice a Sertoli cell lying on the basal lamina $(\rightarrow)$ of the seminiferous tubule, with oval nucleus $(\mathrm{N})$, prominent nucleolus and infolding of its nuclear envelope .Notice also the adjacent Spermatogonia (SG) and an overlying primary spermatocyte (SC). Nucleus(N 1) of a myoid cell is seen outside the basal lamina.

Fig. [9]: A primary spermatocyte with a central large spheria nucleus $(\mathrm{N})$ and copious cytoplasm containing cell organelles. Notice mitochondria (M) with short ill defined cristae. 

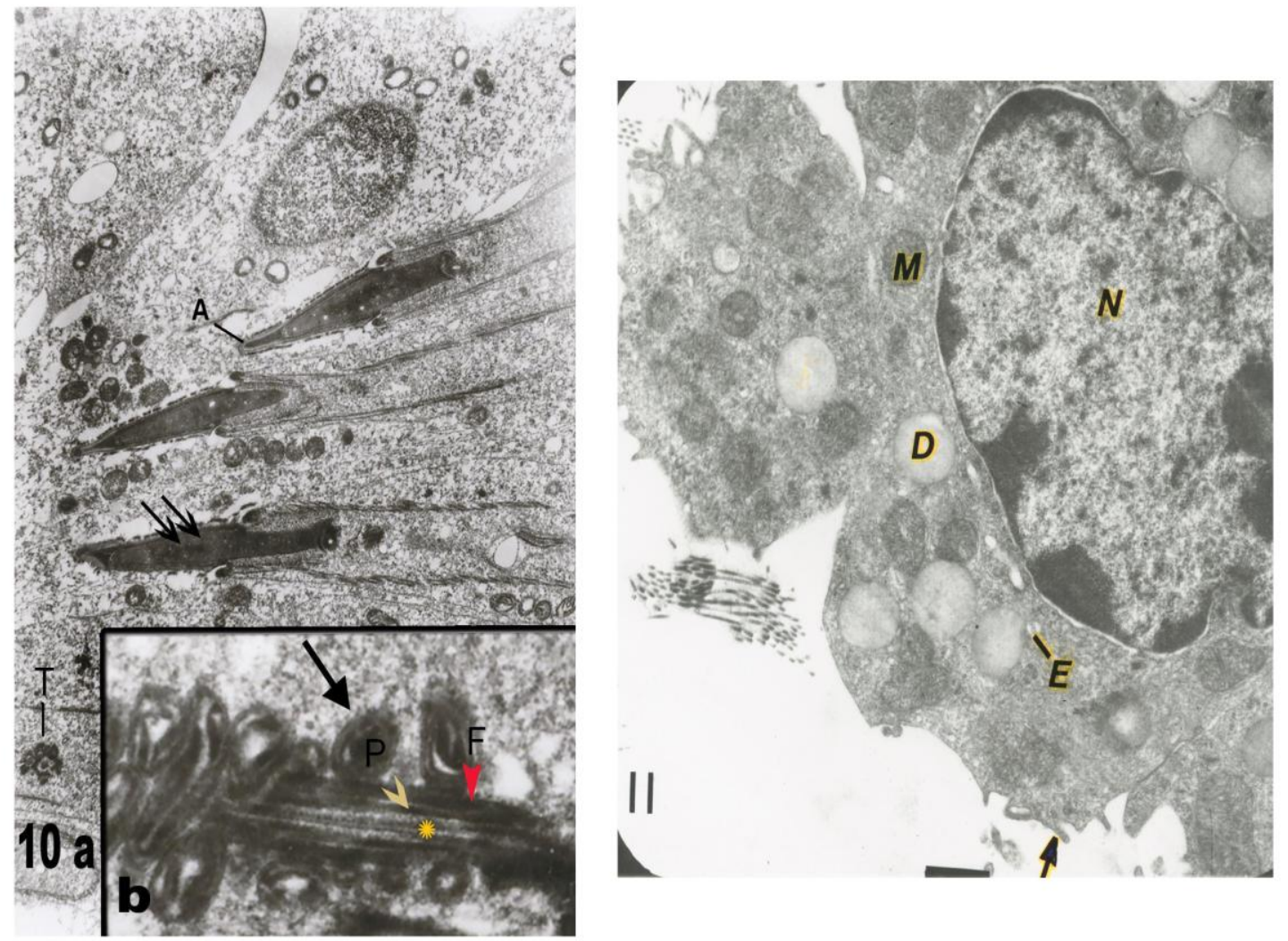

Plate V: Electron micrographs of sections of testies of control adult mice showing:

Fig. [10a]: A sperm with head containing deeply condensed nucleus $\underset{\rightarrow}{\rightarrow}$ ) and acrosomal cap

(A).A cross section of the tail ( $\mathrm{T})$ is seen.

(X5280)

Fig.[10b]: The middle piece of a sperm with central microtubules $\left(^{*}\right)$, peripheral microtubules $(\mathrm{P})$, outer dense fibres $(\mathrm{F})$ and mitochondrial sheath $(\rightarrow)$.

Fig. [11]: An interstitial cell of Leydig. Notice the nucleus (N) surrounded by cytoplasm containing moderate amount of lipid droplets (D), numerous mitochondria (M) and profuse smooth endoplasmic reticulum $(\mathrm{E})$. Microvilli $(\rightarrow)$ are also seen protruding from the cell.

(x6000) 

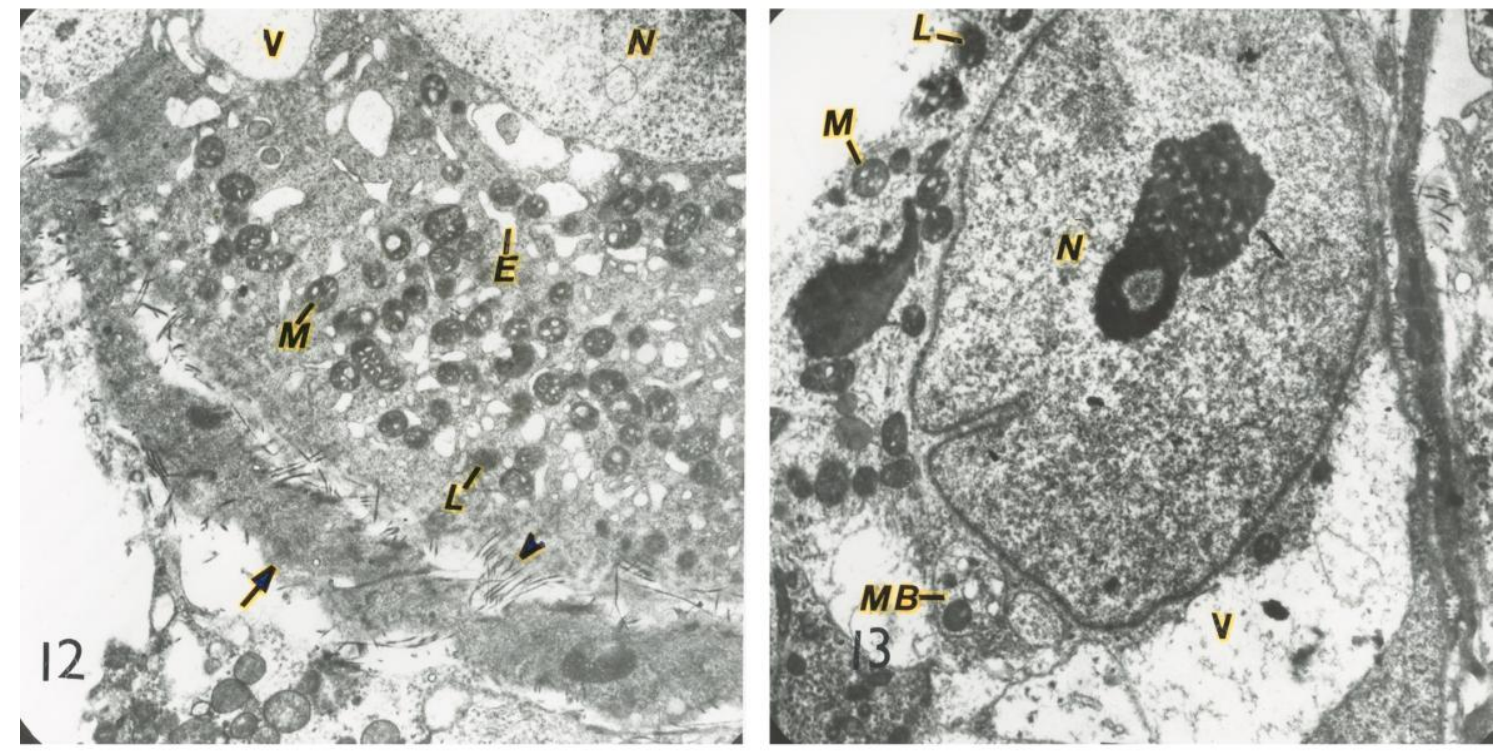

\section{Plate VI: Electron micrographs of sections of exposed testes of adult mice showing:}

Fig. [12]: Part of a degenerating Sertoli cell with pale nucleus(N)lying on basal lamina $(\rightarrow)$.Notice presence of vacuolation $(\mathrm{V})$, degenerated vacuolated mitochondria $(\mathrm{M})$, lysosome (L) and dilated endoplasmic reticulum (E) in the cytoplasm. Notice also separation of Sertoli cell from basal lamina with disrupted collagen fibers (>).

$$
\text { (x4000) }
$$

Fig. [13]: A degenerating Sertoli cell .Notice the nucleus (N) with its characteristics indentation. Electronlucent areas (V) are seen in the cytoplasm. Notice also the presence of degenerated vacuolated mitochondria (M), multi-vesicular bodies (MB) and lysosomes (L).

(x4000) 


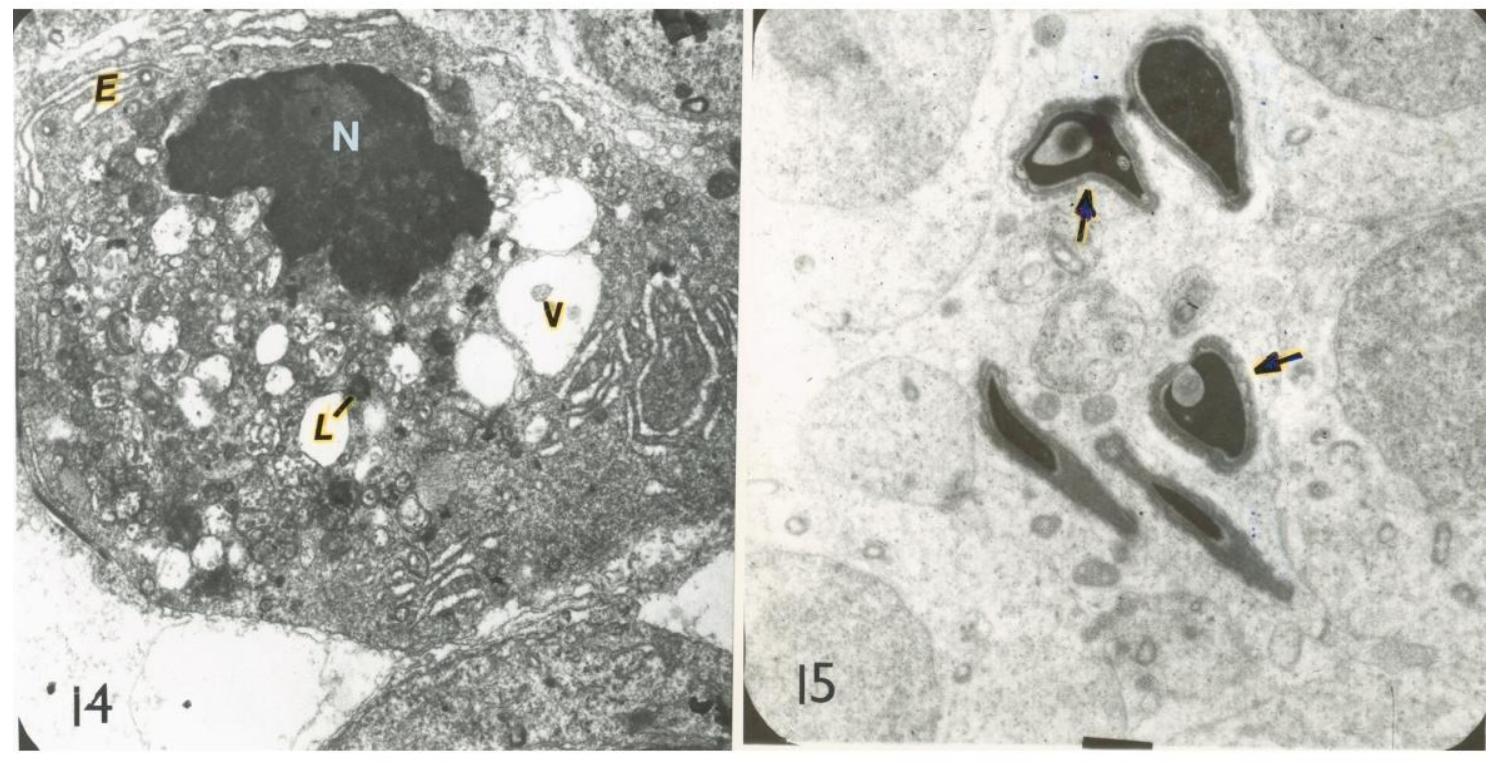

PlateVII: Electron micrographs of a sections of exposed testes of adult mice showing:

Fig. [14]: Primary spermatocyte with irregular pyknotic shrunken nucleus $(\mathrm{N})$. Notice the presence of vacuolation $(\mathrm{V})$, dilated smooth endoplasmic reticulum $(\mathrm{E})$ and lysosomes $(\mathrm{L})$ in the cytoplasm.

Fig. [15]: Abnormal sperms with abnormal heads $(\rightarrow)$. 


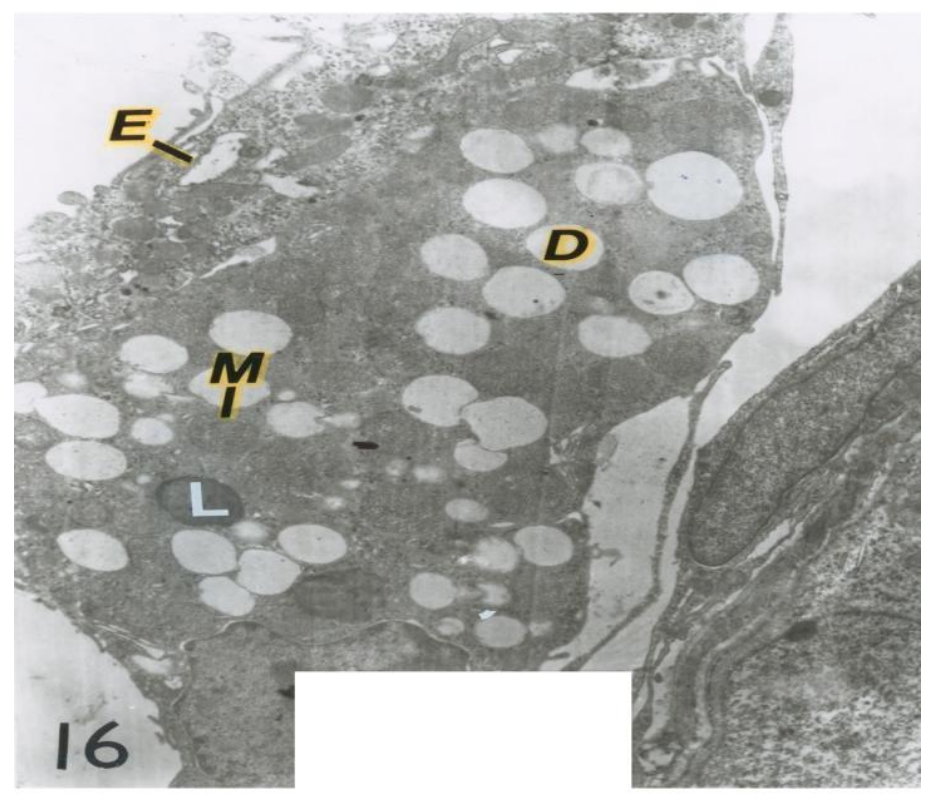

\section{Plate VIII:}

Fig. [16]: An electron micrograph of a section of an exposed testis of an adult mouse showing a Leydig cell. Notice the dilated smooth endoplasmic reticulum (E). Lipid droplets (D) are numerous in the cytoplasm. The mitochondria (M) and lysosomes $(\mathrm{L})$ are normal.

(x4900)

\section{Discussion}

\section{A. The Brain}

The present study showed that exposure to ElMF, caused degeneration of nerve cells with demyelination of nerve fibers. This was in accordance with Salford et al.(2003) who observed dark or damaged neurons in the cortex of rat brain following acute exposure(2hrs)to ELMF of different strengths. This was accompanied by pathological leakage of albumin through the BBB. The neuronal albumin uptake might cause organelle cell damage with release of hydrolytic lysosomal enzymes. Lui et al. (2003) stated that exposure to $50 \mathrm{~Hz}, 0.2$ or $6 \mathrm{mT}$ electromagnetic fields for 2 weeks induced apoptosis and cell cycle alteration of mouse brain. Acute exposure( $2 \mathrm{hrs})$ to $60 \mathrm{HZ}$ sinusoidal magnetic field at intensities 0.1-0.5 $\mathrm{mT}$ showed an increase in DNA single and double breaks in rat brain cells (Lai and Singh, 1997). Prolongation of exposure time to $24 \mathrm{hrs}$ then $48 \mathrm{hrs}$ caused cumulative increase in DNA single and double strand breaks(Lai and Singh,2004).Other studies investigated a damage in DNA of mice brain after 32 days of exposure to $7.5 \mathrm{uT}$ (Svedenstal et al.,1999). DNA strand breaks might affect cellular functions, lead to carcinogenesis and cell death and be related to onset of neurodegenerative disease(Lai and Singh, 2004). This might offer another explanation for the degenerative changes observed in the present work. Bersoni et al. (1997) reported that electromagnetic field exposure caused the biological macromolecule to rotate to achieve minimal energy causing splitting and subsequent recombination of the molecules leading to structural changes 
in the cellular proteins as a whole. On the contrary, Fritze et al. (1997), using immunohistochemical method, found no histological injury to the brain of rat on exposure to microwave for a duration of 4 hrs at a specific absorption rate ranging from $0.3-7.5 \mathrm{w} / \mathrm{Kg}$. This might be due to different techniques used.

Another mechanism for ELMF induced brain affection is inhibition of brain glucose uptake from circulation, which might have resulted from alteration of blood flow through the brain (Sienkiewicz et al., 1993), or failure of the metabolic activity of the red blood cells and the damage of the heart muscle due to prolonged exposure of the animals to ELMF (Ali et al., 2003). The brain has an absolute dependence of the blood for its immediate supply of oxygen and energy substrates. Interruption of oxygen or substrate supply due to impaired pulmonary or cardiovascular function or metabolic factors result in encephalopathy and, ultimately cell death (Butterworth, 1999).

In the present work, the intercellular junctions between endothelial cells of the blood capillaries were intact. This was in accordance with Franke et al. (2005) who reported negative results in vitro on $\mathrm{BBB}$ models exposed to ELMF. On the contrary, Schirimacher et al. (2000) reported that magnetic field increased the permeability of the blood brain barrier and increased the intercellular clefts and decreased the zona occludens protein. This controversy might be due to different techniques used where immunohistochemistry is needed for further investigation.

Several explanations for ELMFinduced affection of cell membrane had been postulated. Bell et al. (1992) reported that magnetic field passing through the body would actually induce electric current within the tissues due to its interaction with electrolyte flow. The magnetically induced electric field in the tissues may induce changes in the cell surface receptor molecules and ion binding to the membrane surface (Varani et al., 2002 and $\mathrm{Xu}$ and Loew, 2003). This may cause alteration of the proportion of opened gates which influence membrane permeability. The change in the gating mechanisms influences the membrane transport of cations such as calcium (Kim et al., 1998 and Lai and Singh, 2004). ELMF influences hormonereceptor interaction, adenylate cyclase activity and membrane transport and intracellular concentration of calcium and /or iron (Burchard et al., 1999 and Takahashi et al., 2005). Linz et al. (1999) reported increased calcium efflux from the cells with subsequent decrease in $\mathrm{Ca}++$ binding to the glycocalyx of the cell membrane which in turn changes the excitability of the cells. This might correlate to the vacuoles encountered in the myelin sheath in the present work which might be oedmatous vacuoles.

\section{B. The Testis}

As regards the testis, the present work revealed significant increase in serum testosterone with degenerative changes in seminiferous tubules and abnormal sperm morphology without marked affection of Leydig cells.

The elevated testosterone level was in agreement with Forgaces et al. (1998) who reported that sinusoidal $50 \mathrm{~Hz} 100 \mathrm{mT}$ magnetic fields exposure for $48 \mathrm{hrs}$ were able to stimulate the basal testosterone production of primary mouse Leydig cell culture. Forgaces et al. (2003) added that the ELMF induced elevation in serum testosterone could be due to an elevated cAMP level. It is known that cAMP is one of the most important second messengers in Leutinizing hormone(LH) receptor mediated steroidogenesis by Leydig cells.

The elevated serum testosterone in the present work could be correlated with the proliferation of the endoplasmic reticulum of Leydig cells. The increase in serum testosterone without marked affection of Leydig cell could be attributed to hormonal disturbance and not to direct testicular injury as suggested by Larch et al. (2001).

On the contrary, Al-Akhras et al . (2005) reported that ELMF $(50 \mathrm{~Hz}, 25 \mathrm{uT})$ for 12 consecutive weeks resulted in marked reduction in serum testosterone, $\mathrm{LH}$ and FSH in adult male rats. Ozyguner et al. (2005) reported similar results. This 
discrepancy might be attributed to difference in animals used, exposure period, intensity and environmental conditions.

The degenerative changes in seminiferous tubules are in accordance to Sert et al.(2002) and Lee et al. (2004) who reported that exposure to ELMF resulted in reduction in the number of well organized seminiferous tubules, increased germ cell death and apoptosis, whereas, Ozyguner et al. (2005)found that exposure to ELMF resulted in reduction in diameter of seminiferous tubules and mean height of germinal epithelium. Sert et al.(2002) added that in ELMF exposed rats, abnormal shapes of sperm with abnormal heads were observed. This was in accordance with the present study. Also, decrease in sperm count and motility were reported after exposure of mice to $20 \mathrm{mT}$ for $3 \mathrm{hrs}$ (Ramadan et al.,2002). Hong et al. (2003) and Hong et al. (2005) reported similar results in addition to changes in sperm chromatin structure. This might lead to structural changes.

Magnetic field exerts its action on the testis by various ways as change in enzymatic activity (as lactate dehydrogenase isoenzyme) within the testes (Afroineev and Tkachenko, 1999), decrease in fatty acid composition of membrane phospholipids fraction of testicular cells(Sert et al.(2002), decrease DNA synthesis or gene expression changes which provoke disturbances in cell metabolism, melatonin secretion and DNA breaks (Lai and Singh, 2004). Magnetic fields could also induce changes secondary to oxidative stress (Ozturk et al., 2003).

On the contrary, ELMF had neither clastogenic effect on sperm chromosomes after exposure to $(50 \mathrm{~Hz}, 20 \mathrm{mT})$ for $2 \mathrm{hrs}$ (Tateno et al.,1998) nor on sperm morphology, count and motility after in utero and neonatal exposure (Chung et al. ,2005).Forgacs et al.(2004) reported that exposure to ELMF of $50 \mathrm{~Hz}, 100 \mathrm{uT}$ for 14 days had no effect on mice testicular tissues. Guler et al. (2005) reported similar results. This discrepancy might be attributed to difference in animals used, exposure period, intensity and environmental conditions

In conclusion, the present study showed evident biochemical and histopathological changes of ELMF on the brain and testis. Further studies would be useful to assess the controversy, effect of other doses of exposure and to follow the degree of reversibility of these changes. It is also advisable to conduct other studies concerning protection from ELMF and minimizing the above biological effects.

\section{References}

1. Afroineev VI and Tkachenko VN (1999): Changes in the percent of lactate dehydrogenase isoenzyme level in testes of animals exposed to super high frequency radiation. Biafizika, (oct) 44.(5), 931-932.

2. Al-Akhras MA, Darmani H, Elbetieha A, (2005): Influence of $50 \mathrm{~Hz}$ magnetic field on sex hormones and other fertility parameters of adult male rats. Bioelectromagnetics, 27:127-131.

3. Ali FM, Sami W and Mohammed MR (2003): Effect of $50 \mathrm{~Hz}, 0.2 \mathrm{mT}$ magnetic field on red blood cells properties and heart functions of albino rats. Bio electromagnetics, 1:7-11.

4. Altman DG (1994): Practical statistics for medical research, Chap. 9, $1^{\text {st }}$ edn., Chapman and Hall, London, NY, p 218.

5. Arutiunian LL, Danielian AA, Guigorian GE and Airepetian SN (1998): Senstivity of different tissues of rats to the effects of a permanent magnetic field. Radiats Biol. Radioecol Nov-Dec, 38(6):913-915.

6. Bell GB, Marino AA, Chesson AL and Stouve FA (1992): Electrical states in the rabbit can be altered by light and electromagnetic fields. Brain Res., 570: 3007-3010.

7. Bersoni F, Marinelli F, Ognibene A and Maraldi N (1997): Intramembrane protein distribution in cell cultures is affected by $50 \mathrm{~Hz}$ Pulsed magnetic field. Bioelectromagnetics, 18 (7): 463-469.

8. Boorman GA, McCormic DJ, Ward JM and Sills, RC (2002): Magnetic field and mammary cancer in rodents: A critical review and evaluation of published literature. Radiat Res., 153: 617-626.

9. Burchard JF, Naguyen DH and Block E (1999): Macro and trace element concentrations in blood plasma and cerebrospinal fluid of diary cows exposed to electric and magnetic fields. Bioelectromagnetics. 20 (6): 358-364.

10. Butterworth $R$ (1999): Metabolic encephalopathies. In: Basic neuroche- 
mistry. Siegel G., Agranoff, Albers R, Fisher, $\mathrm{S}$ and Uhler $\mathrm{M}$ (eds), $6^{\text {th }}$ edition, Lippincott Philadelphia and London. Chapter, 38: 769.

11. Chung MK, Lee SJ, Kim YB, Park SC, Shin DH, Kim SH and Kim JC (2005): Evaluation of spermatogenesis and fertility in F1 male rats after in utero and neonatal exposure to extremely low frequency EMF. Asian J Androl., Jun; 7 (2): 189-94.

12. David CR, Williams ID and Wilkins DG (2002): Basic restrictions in EMF exposure guidelines. Healthy Phys., 83 (3): 395-401.

13. Forgaces $\mathbf{Z}$, Somosy $\mathbf{Z}$,Gyorgyi $\mathbf{K}$ et al. (2004): Effects of whole body $50 \mathrm{~Hz}$ magnetic field exposure on mouse Leydig cells.The Scientific World Journal, 4 ;83-90.

14. Forgaces Z, Somosy Z, Rovesz $\mathbf{C}$ et al. (2003): Effect of $50 \mathrm{~Hz}$ magnetic field exposure on the adherent cell contacts of primary mouse Leydig cells in culture. Acta Biologica Szegediensis, 47 (1-4): 27-30.

15. Forgaces Z, Thuroczy G, Paksy $\mathbf{K}$ and Szabo D (1998): Effect of sinusoidal 50 $\mathrm{Hz}$ magnetic field on the testosterone production of mouse primary Leydig cell culture. Bioelectromagnetics, 19: 429431.

16. Franke H, Streckert J, Bitz A, Goeke J, Hansen V, Ringelstein EB, Nattkamper H, Galla HJ, Stogbaver F (2005): Effects of Universal Mobile Telecommunication System (UMTS) electromagnetic fields on the blood brain barrier in vitro. Radiat Res 164(3): 25869.

17. Fritze K, Sommer C, Schmitz B, Mies G, Hossmann KA, Kiessly $M$ and Wiessner C (1997): Effect of global system for mobile communication(GSM) microwave exposure on blood brain barrier permeability in rat. Acta Neuropathologica, 94(5): p 465-470.

18. Guler G, Hardalac F and Aricioglu A (2005): Examination of electric field effects on tissues by using back propagation neutral network. J Med Syst., Dec; 29 (6): 679-708.

19. Hayat AM (1989): Principles and techniques of electron microscopy. Vol. (1). Van Nastrano Reinhold, Ltd. P. 27-74.

20. Hong R, Liu Y, Yu YM, Hu $\mathbf{K}$ and Weng EQ (2003): Effects of extremely low frequency EMF on male reproduction in mice. Zhonghua Lao Dong Wei Sheng Zhi Ye Bing Za Zhi, Oct., 21(5): 342-5.

21. Hong R, Zhang Y, Liu $\mathbf{Y}$ and Weng EQ (2005): Effects of extremely low frequency EMFs on DNA of testicular cells and sperm chromatin structure in mice. Zhonghuo Lao Dong Wei Sheng Zhi Ye Bing Za Zhi, 23 (6): 414-7.

22. Kim YV, Conover DL, Lotz WG and Cleary SF (1998): Electric field induced changes in agonist stimulated calcium fluxes on human HL-60 leukemia cells. Bioelectromagnetics, 19 (6): 366-76.

23. Kuribayashi M, Wang J, Fujiwara O, Doi Y, Nabae K, Tamano S, Ogiso T, Asamato M, Shirai T(2005):Lack of effects of $1439 \mathrm{MHz}$ electromagnetic near field exposure on the blood brain barrier in immature and young rats. Bioelectromagnetics, 26 (7): 578-88.

24. Lai $H$ and Singh NP (1997): Acute exposure to $60 \mathrm{~Hz}$ magnetic field increases DNA strand breaks in rat brain cells. Bioelectromagnetics, 18:156-165.

25. Lai $\mathrm{H}$ and Singh NP (2004): Magnetic field induced DNA strand breaks in brain cells of the rat. Environ. Health Perspect, 112 (6): 687-94.

26. Larch H, Brendel A, Bitz A, Streckert $J$ and Hansen V (2001): Further evidence for increased testicular proliferation in Hamsters by exposure to electromagnetic fields(900 $\mathrm{MHZ}$ and 1800 MHZ) National High Magnetic Laboratory Ferner@ Magnet. Fsu.edu.

27. Lee JS, Ahn SS, Jung KC, Kim YW and Lee SK (2004): Effects of $60 \mathrm{~Hz}$ EMF exposure on testicular germ cell apoptosis in mice. Asian J Androl., Mar; $6(1): 29-34$.

28. Linz KW, Westphalen C, Streckert J, Hansen $V$ and Meyer $R$ (1999): Membrane potential and currents of isolated heart muscle cells exposed to pulsed radio frequency fields. Bioelectromagnetics, 20:497-511.

29. Lui Y, Hong R, Yu YM, Weng EQ (2003):Effects of extremely low frequency electromagnetic fields on apoptosis and cell cycle of mouse brain and liver cells.Zhonghua Lao Dong Wei Sheng Zhi Ye Bing Za Zhi, 21(5): 339-41.

30. Mc Carm DS, Kirkish LS (1985): Evaluation of free testosterone in serum. J. Clin. Immunoassay, 8:234-236.

31. Otter MW, McLeod KJ and Rubin CT (1998): Effects of electromagnetic fields 
in experimental fracture repair. Clin. Orthoped. , 355S Suppl.90-104.

32. Ozturk A, Baltaci AK, Mogulkoc $\mathbf{R}$ and Oztekin E (2003): Zinc prevention of electromagnetically induced damage to rat testicle and kidney tissues. Biol. Trace Elem. Res., 96 (1-3): 247-54.

33. Ozyguner M, Koyu A, Cesur G, Ural M, Ozguner F, Gokamen $A$ and Delibas N (2005): Biological and morphological effects on the reproductive organ of rats after exposure to EMF. Saudi Med J. Mar. 236 (3): 405-10.

34. Preece AW (1997): Magnetic fields from domestic appliances in the UK. Phys Med Biol 42: 67-76.

35. Ramadan LA, Abd-Allah AR, Aly HA and Saad-El-Din AA(2002): Testicular toxicity effects of magnetic field exposure and prophylactic role of coenzyme Q10 and L- Carnitine in mice. Pharmacological Research, 46(4): 363-370.

36. Saad El-Din AA, Saad HN and Said HH (2000): The design construction and application of time varying magnetic field Exposure. Seventh conference of nuclear science application. Cairo. Egypt, 1072-1084.

37. Salford LG, Brun AE, Eberhardt JL, Malmgren L, Persson BR (2003): Nerve cell damage in mammalian brain after exposure to microwaves from GSM mobile phones.Environ Health Perspect 111 (7) : 881-3.

38. Santini MT, Ferrante A, Rainaldi G, INdovina $P$ and Indovina PL (2005): Extremely low frequency (ELF) magnetic fields and apoptosis: a review. Int. J Radiat. Biol., 81 (1): 1-11.

39. Schirimacher A, Winters S, Fischer S, Goeke J, Galla HJ and Kullnick U (2000): Electromagnetic fields increase the permeability to sucrose of the blood brain barrier in vitro. Bioelectromagnetics, (Jul). 21 (5): 338-345.

40. Sert C, Akdag MZ, Bashan M, Buyukbayram H, AND Dasdag S (2002): ELF magnetic field effects on fatty acid composition of phospholipid fraction and reproduction of rats testes. Electromagnetic Biology and Medicine, 21: 19-29.

41. Sienkiewicz ZJ, Cridland NA and Saunders RD (1993): Biological effects of electromagnetic fields and radiation. In: The Review of Radio Science, Stone, WR and Hyde G (eds), Oxford University Press, Oxford, UK, Chapter 7, p. 737.

42. Simko M (2004): Induction of cell activation processes by low frequency EMFs. Scientific World Journal, 20: 4 suppl. 2: 4-22.

43. Svedenstal BM, Johanson KJ,Mattsson MO,Paulsson LE (1999): DNA damage cell kinetics and ODC activities studied in CBA mice exposed to electromagnetic fields generated by transmission lines. In Vivo, 13 (6): 507-13.

44. Takahashi K, Doge $\mathbf{E}$ and Yoshioka $\mathbf{M}$ (2005): Prolonged $\mathrm{Ca}^{+2}$ transients in ATP stimulated endothelial cells exposed to 50 $\mathrm{Hz}$ electric field. Cell Biol. Int., 29 (3): 237-43.

45. Tateno H,Iijima S, Nakanishi Y, Kamiguchi Y, Asaka A (1998): No induction of chromosome aberrations in human spermatozoa exposed to extremely low frequency electromagnetic fields. Mutat Res, 414(1-3): 31-5.

46. Valberg PA (1996): Can low level 50/60 $\mathrm{Hz}$ electric and magnetic fields cause biological effects. Med. Res., 148: 2-21.

47. Varani K, Stefania $\mathbf{G}$ and Borea $\mathbf{P}$ (2002): Effect of low frequency electromagnetic fields on A2 adenosine receptors in human neutrophils. Brit. J. Pharmacol., 136: 57-66.

48. Xu C and Loew LM (2003): Activation of phospholipase C increases intramembrane electric fields in NIE-115 neuroblastoma cells. Biophys. J., 84 (6): 4144-56.

49. Yasui M (1997): Carcinogenicity test of $50 \mathrm{Mz}$ sinusoidal magnetic field in rats. Bioelectromag netics,. 8: 531-540. 
تقييم التغيرات التركيبية الناتجه عن المجالات المغناطيسة ذات التئي التردد

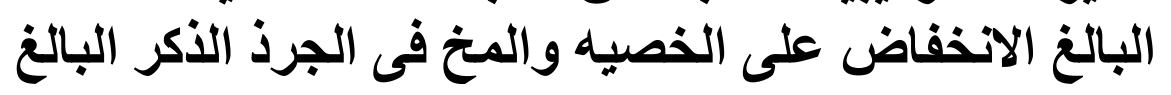

*عائشة سعد الدين - * نبيلة عبد الرحمن عبد المتعال- **هايدى فريد عبد الحميا

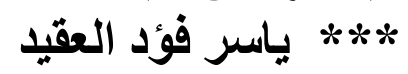

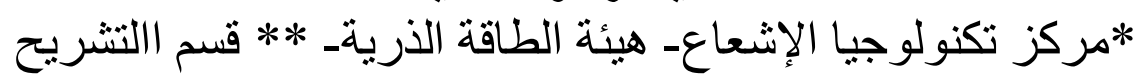

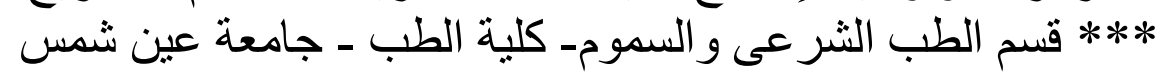

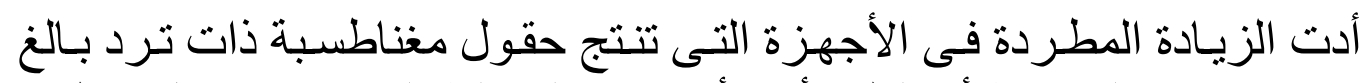

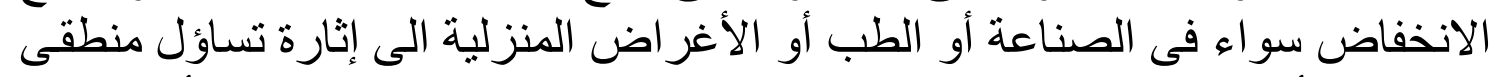

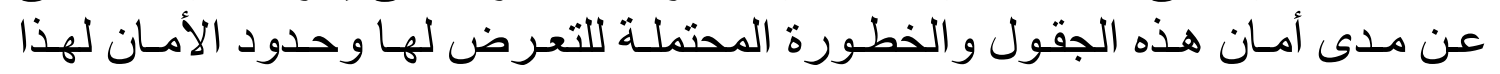

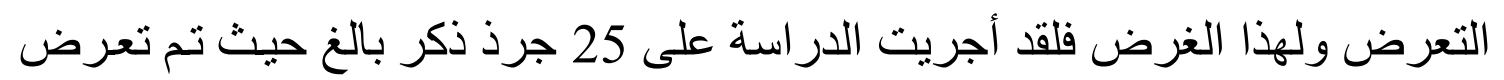

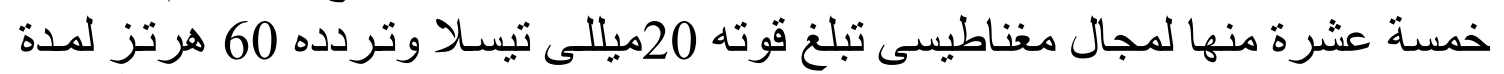

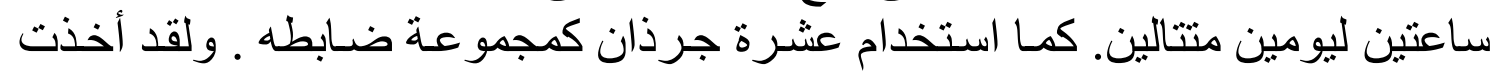

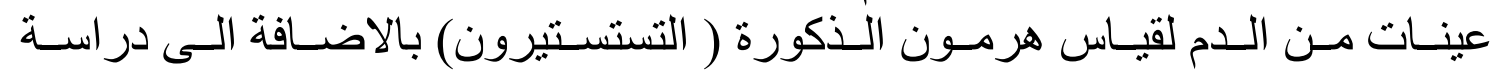

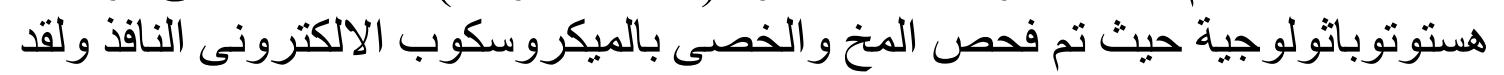

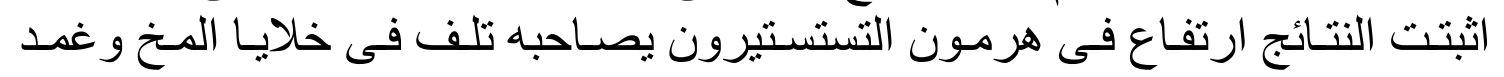

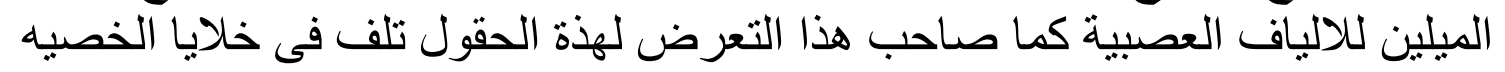

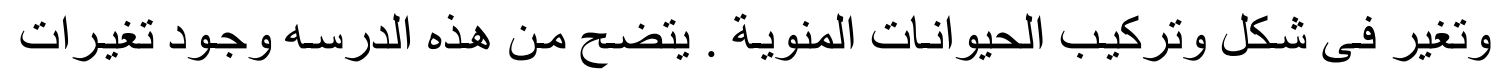

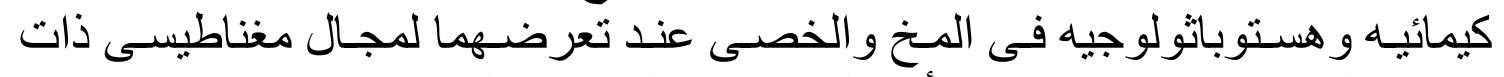

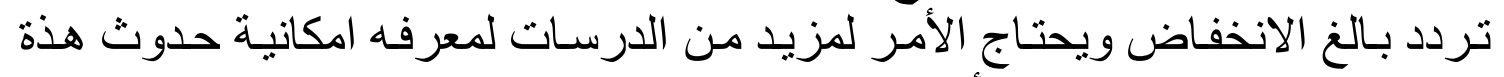

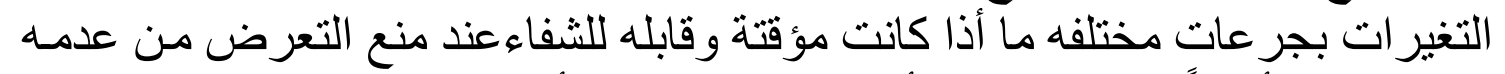

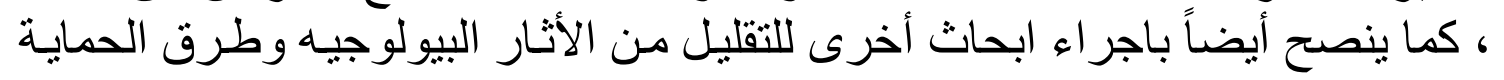

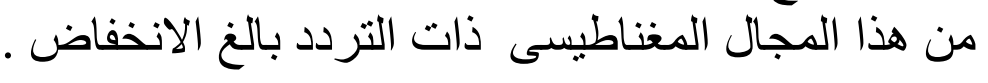

